\title{
Approaches for Reducing Urban Traffic Congestion in the City of Harare
}

\author{
Shakerod Munuhwa* King Muchenje Johanna Pule Tendai Mandere Tendani Gabakaiwe \\ Business Management Department, BAISAGO University, Bag 149, Gaborone, Botswana
}

\begin{abstract}
Traffic congestion is a major challenge in the city of Harare, especially in the central business district (CBD) resulting in massive delays, a decrease in productivity and an increase in environmental pollution. Therefore, the study sought to assess the management of traffic congestion in Harare urban. The study employed an exploratory design to sample 315 respondents through the administration of questionnaires. In-depth interviews were conducted with seven officials of management institutions in Harare. Quantitative data were analysed using SPSS $\mathrm{v} 21$ whereas the qualitative data was manually analysed. The study revealed that massive influx of motor vehicles in the city, bad attitude of drivers (especially commuter omnibus and tax drivers), poor or no urban transport policy framework, vendors all over the traffic ways; massive pedestrians population in the CBD and Road Traffic Crashes (RTCs) were the main causes of traffic congestion. The effects of traffic congestion are decreasing sales, higher transport costs, pollution, decreased productivity and stress to motorists as a result of longer travelling time. The study recommends implementation of mass transit system in transporting public within the CBD, public education, strict enforcement of road traffic regulations, construction of proper vendor selling points in the CBD, provision of adequate parking spaces to help manage traffic congestion in Harare CBD as well as implementation of smart urban transportation and mobility technologies.
\end{abstract}

Keywords: Congestion, central business district (CBD), Harare, mass transit, Zimbabwe

DOI: $10.7176 / \mathrm{JESD} / 11-4-01$

Publication date: February $29^{\text {th }} 2020$

\section{Introduction}

Traffic congestion is one of the worldwide urban problems, which can lengthen journey time, increase energy consumption, reduce industrial and commercial productivity, aggravate environmental pollution and result in traffic accident, (Currie \& Walker ,2011). Urban Traffic congestion has been a problem especially for most big cities in both the developed and developing world and it is predicted to get worse in the future (Kiunsi, 2013). According to (Texas Transportation Institute, 2011), traffic congestion in the US has increased substantially over the last 25 years. The Brazilian city of Sao Paulo is known to have experienced the world's worst traffic jams, where people are stuck for two to three hours every day in traffic jams (Mahendra, 2009). Such situation has obvious implication on productivity and the socio-economic development at large resulting in delays, fuel wastage and money loss (Texas Transportation Institute, 2011 Mobility report).

Harare is the capital, industrial and commercial city of Zimbabwe. It was declared a municipality in 1897 and became a city in 1935. Formerly dubbed 'the sunshine city', Harare has in the last few years been affected by the country's debilitating macroeconomic situation. Notwithstanding the adverse economic environment, the people have found a reasonably cheap source of motor vehicles from Japan and the United Kingdom, (Mbara,2015). Vehicles arrive in the country daily in great quantities and the majority of them are destined for Harare. According to the Central Vehicle Registry (CVR, 2012), the number of vehicles in the country increased by approximately 6\% from 522682 in 1999 to 973188 by 2009. Albeit the non-availability of figures by city, it is estimated that about $70 \%$ of these vehicles are in Harare. Harare CBD traffic congestion is bad, especially in the west of the $\mathrm{CBD}$ at the best of times and intolerable during peak hours. Provision of a reliable, efficient transport system to move goods and labour is required if Zimbabwe is to grow its economy through urban productivity. The country has been urbanising at a high rate. Ironically, as urban population grew, conventional public transport declined. Transportation challenges in Harare has been caused largely by policy interventions in the transport sector such as the Zimbabwe Deregulation of the transport sector in the early 1990s mainly after the failure of the Economic Structural Adjustment Policy (ESAP), (Government of Zimbabwe

1993). The deregulation and other factors in Harare facilitated the informal public transport system which is mainly associated with urban evils such as congestion and chaotic urban public transport system which impacts on the quality of the urban transport environment. Note has been taken that as the informal sector and private motorisation expanded, the city's main urban public space became more congested, impeding rather than facilitating the urban population's ability to access the required social and economic services. A vivid mismatch of the demand for traffic space and its availability is evident.

Demand for traffic space exceeds that of its supply, inevitably resulting in congestion which can be protracted. Demand for transport has increased faster than the City of Harare can provide and is creating health and safety risks, impeding economic development. The increasing public-supply/demand gap compelled the proliferation of 
pirate taxis. There are absolutely no mechanisms within the Harare City Council to reduce congestion in the CBD because council itself does not have its own public transport service. In July 2015, Harare City Council entered into Memorandums of Understanding (MoU) with two local public transport companies to offer scheduled urban passenger transport services in the capital, and the ambitious deal suffered a stillbirth, (The Herald 25 February ,2018)

Despite the recent needless operation by the Harare City Council, the reality is that motorists and pedestrians have suffered at the hands of both commuter omnibuses and illegal pirate taxis, commonly known as "mushikashika". Running battles between the police (Zimbabwe Republic Police and Municipal Police) and public transport providers have left many injured and some even dead. These small cars and minibuses park willy-nilly, blocking other traffic and causing congestion. (The Herald 25 February ,2018)

Further to an influx of vehicles and combis, decomposing economic situation in Zimbabwe have turned many people into town vending in undesignated places mostly in streets in the inner CBD. These vendors display their wares and goodies for sale in the edges of the streets thereby further narrowing the width of most streets. This will then force ever increasing motorists to squeeze and battle for space along very narrow roads and therefore exacerbating the level of congestion within the city. The Harare city council police makes several arrest of such vendors but still they have not yet managed to chase away these vendors as they still flock to sale their goodies in the streets every day, (Mbara,2015)

Therefore, this study seeks to assess the causes and effects of traffic congestion in Harare CBD 'and how it can be managed from the user's perspective. Identifying these characteristics is the first step for efforts because it is an essential guide for selecting appropriate measures (Rao \& Rao, 2012). The following research questions guided this study:

1. What are the causes of traffic congestion in the Harare CBD?

2. What are the effects of traffic congestion in the Harare CBD?

3. What are the possible measures needed to reduce traffic congestion in the Harare CBD?

Studies like this will help improve on managing traffic congestion in the biggest city of Zimbabwe and as such influence policy, which can be replicated in cities and towns across the country. The findings of this study are of importance to urban transport planners, policy makers, vendors, drivers, pedestrians, and shoppers in the Harare Central Business District. It will help elicit the various causes and effects of traffic congestion in Harare CBD. The study will also provide information on the measures to manage traffic congestion in the Harare CBD. This paper anticipates expanding the existing knowledge about tackling traffic congestion in Zimbabwe as a developing country. Furthermore, results of this study can be used to manage existing problems of traffic congestion in Cities of other developing countries with similar characteristics.

The paper is divided into seven sections. Section one is the introduction and background of the study. Following section one is the literature review showing the causes and effects of traffic congestion and how it is being managed. Section three presents the study area with section four containing the research methodology. Section five contains the results with section six presenting the discussion. Section seven concludes with the conclusion and policy implications.

\section{Literature review}

\subsection{Traffic congestion as a concept}

There is no single definition of traffic congestion as it is both a physical and a relative phenomenon (Rahane \& Saharkar, 2014). As a physical phenomenon, it is defined as a situation where demand for road space exceeds supply and is reflected by slower speed, longer trip times and increased motor vehicular queuing (Downie, 2008). It is a relative phenomenon when there is a difference between road performance and road user's expectations (Downie, 2008; Kiunsi, 2013).

Traffic congestion can be perceived as an unavoidable consequence of scarce transport facilities such as road space, parking area, road signals and effective traffic management (Blanco et al., 2009). Urban congestion mainly concerns two domains of circulation, passengers, and freight, which share the same infrastructure. Thus, traffic congestion condition on road networks occurs as a result of excessive use of road infrastructure beyond capacity, and slower speeds, longer trip hours and increased vehicular queuing characterize it. Any city that is economically active and vibrant will rarely be free from traffic congestion (Yildirim, 2001).

\subsection{Types of traffic congestion}

Two types of traffic congestion were singled out, recurrent congestion, and nonrecurring congestion. Recurrent congestion generally occurs at the same place, at the same time every day. This is generally the consequence of factors that act regularly or periodically on the transportation system such as daily commuting or weekend trips, (Victoria Transport Policy Institute, 2009). Recurrent congestion is predictable and typically occurs during peak hours. It displays a large degree of randomness in terms of duration and severity. On-Recurrent Congestion is the effect of unexpected or unplanned large events, example; road works, accidents, special events, and other related 
events or activities that affect transportation system more or less randomly and as such, cannot be easily predicted. The study gives more emphasis on recurrent type of congestion.

\subsection{Causes of traffic congestion}

There are a number of specific circumstances, which cause or aggravate congestion: rapid increase in urban population, economic growth, increase employment opportunities, increase in number of cars and number of people using cars, low capacity of transport infrastructure, road layout, underinvestment in road infrastructure, poor traffic management, shortage of street parking, signal and equipment failure, non-adherence to traffic regulations, poor urban planning or poor urban development control, the rapid expansion of city boundaries, poor public transport, increased use of private cars, car accidents, special events gatherings, road works, and bad weather (Andoh, 2014).

The European Conference of Ministers of Transport (ECMT) (2007) alluded that traffic congestion is caused by a number of factors such as; poor pavements, too many vehicles and motorcycle, land use patterns, employment patterns, income levels, car ownership trend, infrastructure investment, regional economic dynamics, tourism, poor land use integration among other factors.

2.3.1. Causes of traffic congestion in developing countries

The situation has worsened for developing countries due to the following reasons: unplanned cities, poor discipline, alternate traffic means, archaic management, and improper lane management (Mbara ,2015). Unplanned cities: roads are narrow and poorly built. As cities grow in an ad hoc manner, no provision is made towards scaling road capacities, eventually resulting in several bottleneck roads, which remain congested for extended periods of time. Furthermore, many developing countries have witnessed an explosive growth in their vehicular population resulting in a failure of conventional traffic management strategies.

Poor discipline: drivers often are not trained enough to follow lane discipline. The impact of poor lane discipline, especially at traffic junctions, deteriorates the already overcrowded junction situation. Furthermore, drivers frequently jump red lights and block the intersection, causing further traffic congestion. These problems are compounded by the fact that traffic law enforcement is poor, thereby providing no incentive for drivers to follow the rules.

Alternate traffic means: countries with fast-growing economies have witnessed a surge in the number of vehicles across major cities. These cities seldom have efficient mass transit systems, forcing people to operate private vehicles. This problem is compounded by the social stigma, where people view operating a private vehicle as a sign of prosperity, while public transport is viewed as being used by the lower echelons of society, (Shamsher \& Abdullah, 2015)

Archaic management: traffic junctions are often unmanned, thereby allowing drivers to drive in a chaotic manner. Even if a junction is controlled by a police officer or a traffic light, the traffic junctions are largely independent of any traffic management strategy, only optimizing the respective junction traffic flow, in the direction of maximum traffic build up. Furthermore, these approaches enhance traffic mismanagement in already congested roads, accelerating congestion collapse.

Improper lane management: lane management is an important fact in managing the traffic. Many types of vehicles try to overtake other vehicles even in the single undivided road. This is the main reason that the city roads are unequipped with the lane dividers, which divide the lane into incoming and outgoing traffic.

2.3.2. Causes of traffic congestion Harare CBD

According to (Mensah et al, 2014), the causes of traffic congestion in Harare CBD can best be grouped into four categories called horizontal factors, vertical factors, traffic control devices, and loading and dropping of passengers along the road.

\subsubsection{Horizontal causes of Urban traffic congestion}

These factors include poor road network: Transportation engineers have long studied and addressed the physical capacity of roadways, the maximum amount of traffic capable of being handled by a given highway section. Capacity is determined by a number of factors: the number and width of lanes and shoulders of roads; merge areas at interchanges; and roadway alignment (grades and curves). Bad roads cause congestion that results into accidents, it's not all accidents of automobiles that are a result of driver's error but sometimes roads conditions are to blame (Zhang ,2011). Pavement edge drop-offs, bad curves, potholes, poor slope construction, extra cause serious injuries and even death. Pavement edge drop-offs seem to cause serious accidents. When a car's tire drops off one of these edges bounce can occur, causing the driver to over-correct and oftentimes lose control.

Pedestrian obstruction: the missing crosswalks sometimes forces pedestrians to cross the roads at many different parts which eventually leads to congestions in different parts of the same road. The massive flow of population in the CBD results in too many pedestrians encroaching into the vehicle way especially in the down town of the city (Cameroun street, Chinhoyi street, Robert Mugabe street, Mbuya Nehanda street, Harare street, Leopold Takawira street, to mention just a few). 


\subsubsection{Vertical causes of road congestion.}

Trading obstruction is events that disrupt the normal flow of traffic, usually by physical impedance in the travel lanes. In addition to blocking travel lanes physically, events that occur on the shoulder or roadside can also influence traffic flow by distracting drivers, leading to changes in driver behaviour and ultimately degrading the quality of traffic flow. Influx of vendors along several roads in Harare CBD has a considerable contribution towards traffic congestion as these traders eat a lot of parking and roadway space. More to this these vendors are often in a cat and mouse hunt with the municipal police who will be trying to chase them away from blocking the traffic way, during this chase process most of these vendors flock into the middle of the roads with their goodies as they flee from police and further obstructing the movement of traffic, (Mbara, 2015).

Narrow traffic lanes: Construction of roads with narrow lanes several years ago is now causing serious congestions in Harare CBD.

Reserved Parking lots: It was observed from most of these arterial roads that the various shops, offices, and churches along it had either no or inadequate parking spaces. As results of this, a lot their customers tend to park their cars along the shoulders of the road. Lack of pullouts or designated stopping points for delivery vehicles within the CBD results in numerous interruptions to flow of the vehicles, even within non-conflicting streams of traffic, which seriously contribute to the road congestion.

2.3.2.3 Traffic control devices traffic control congestion.

Intermittent disruption of traffic flow by control devices such as traffic lights not working railroad grade crossings and poorly timed signals also contribute to congestion and travel time variability. Harare like any other part of Zimbabwe is experiencing massive load shedding sometimes up to more than 8 hours of load shedding. As much as most traffic lights work with electricity during all this time that the CBD is under electricity load shedding, traffic will usually be locked on several intersections causing many hours of traffic congestion across several intersections within the city.

2.3.2.4 Loading and picking off passengers along the road.

In Harare, most of the commuter omnibuses, taxis and informal vehicles (known as Mushikashika) do not have permanent terminals and routes. They move around picking passengers and dropping them along the routes. These informal public transport vehicles can also be boarded anywhere along the routes which obviously cause road traffic congestion in the city.

\subsection{Effects of traffic congestion}

The effects of traffic congestion can be categorized into four main groups of environmental, economic, health and social (Mahmud et al., 2012). The nature, extent, and severity of the effects differ from one city to another depending among other things the city size, road capacity and road layout, spatial distribution of land use, modes of public and private transport systems and travel patterns (Kiunsi, 2013).

(Mahmud et al ,2012) expounded that traffic congestion increases travel cost, he mentioned various costs caused by traffic congestion, traffic slows down speed which is a visible cost and when people forgo their trips because of fear for congestion then it becomes a hidden cost of congestion and when traffic congestion make people not to believe in their cities they miss finding better jobs, and sharing better amenities

Despite the growing number of hybrid vehicles on the road, cars stopped in traffic still produce a large volume of harmful carbon emissions. Besides contributing to global warming, these emissions can cause more short-term and localized problems, such as smog and increased respiratory problems in a community due to poor air quality. Commuters who are exposed to air pollution, like those riding in non-air conditioned vehicles, double their health risk. Aside from stress, they are also exposed to pollutants that can affect the lungs.

The economic impacts are increasing in fuel consumption, which leads to higher transportation costs, wastage of working time and delay in service delivery which mainly reduces overall urban productivity. Borrowed from the Herald 8 June 2018, South Africa loses R1.5 billion annually as a result of urban traffic congestion while Egypt's capital Cairo loses $\$ 8$ billion annually which is about $4 \%$ of that country's Gross Domestic Product. The impact on Zimbabwe is obviously colossal if thriving economies such as South Africa and Egypt can feel it to such levels. Health impacts, which primarily occur due to extended exposure to polluted air and unnecessarily long periods spent on roads, are mental stress, tiredness, and headache. Social impacts include a reduction in quality of life as reflected by a reduction in personal incomes due to increased transportation costs and less productivity, loss of time that could have otherwise been spent on social activities (Mbara, 2015). Drivers who become impatient may be more likely to drive aggressively or dangerously. This contributes to poor health for those affected by the stress and puts other drivers in danger. Road rage also increases the danger posed to pedestrians on the roads, vendors and fellow motorists. 


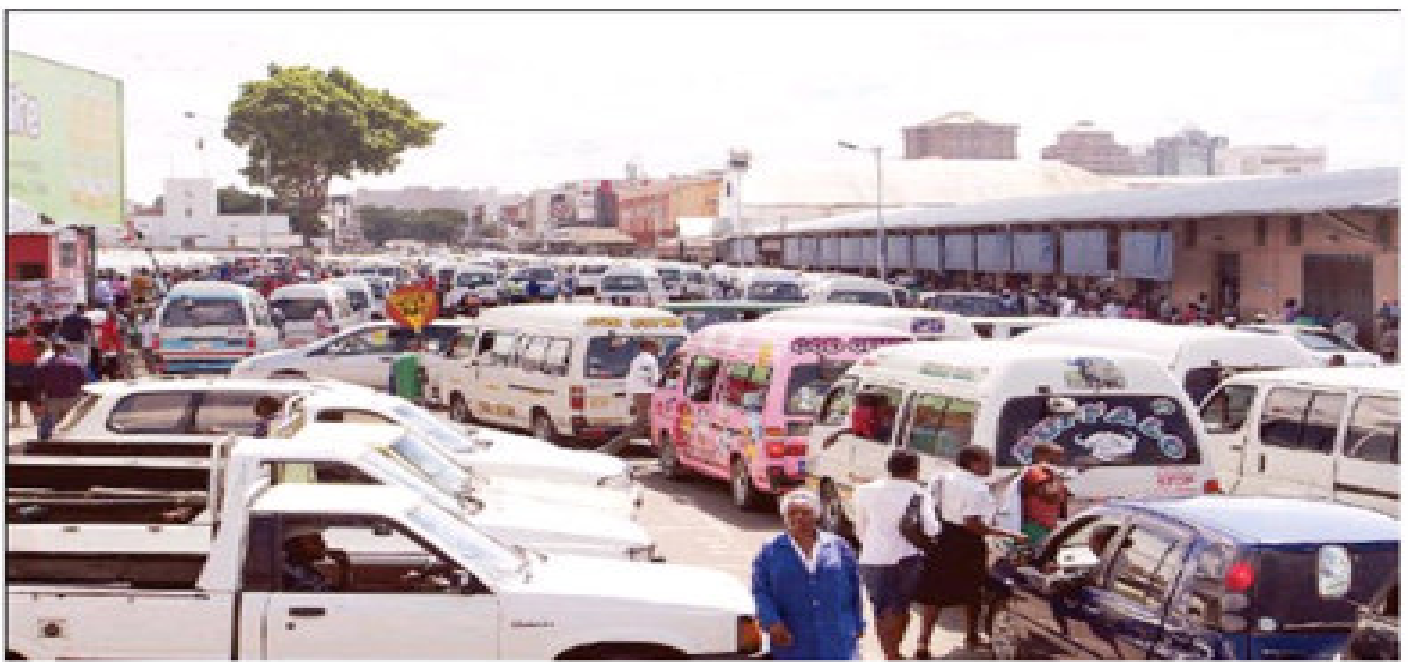

Fig 1: Harare down Town congestion (Market Square Area)

Source: Field survey 2019

\subsection{Managing traffic congestion}

Traffic congestion in urban areas cannot be completely eliminated but can only be minimized to an acceptable level and its approach is multi-faceted. Rodrigue, Comtois, and Slack (2009) outline some measures that could help deal with the congestion menace-traffic signal synchronization, incident management, congestion pricing and the use of public transit as possible effective strategies available in dealing with congestion situation, although not without their associated challenges.

2.5.1 Mass Transit Transport system

The mass transport system is a reasonable suggestion because the present public transport system is characterised by small vehicles and the operations are fragmented and inefficient as they are run by individuals. Secondly, mass transit vehicles carry a far higher number of passengers, making them an efficient user of road space, ultimately decongesting the city. Thirdly, due to their sizes and ability to carry people in mass, the cost per passenger kilometre is lower, making them affordable to users. Fourthly, as mass transit systems carry more efficient engines, they can save fuel better than small vehicles. Finally, their impact (negative effects) on the external environment is lower compared to small vehicles. Mass transit vehicles therefore provides solutions to the economic, social, energy and environmental challenges in the city. The legislative framework for mass transport system in Zimbabwe is already in place, but what is required is a commitment by stakeholders to implement the policy. There are three possible options for the implementation of that policy:

Minibus operators forming an association to acquire conventional buses or empowering the current operators to acquire bigger buses, Franchising high-demand corridor routes, and Public Private Partnerships (PPPss) Harare City Council is facing grave challenges which, inter alia, include an increase in population and the number of motor vehicles, a deteriorating transport infrastructure, an inefficient public transport (if ever there is any) and a high rate of accidents. All these snags have implications on achieving a sustainable transport and hence the need to raise the question on the requirements of achieving sustainable transport for the city. If there shall be no consensus on the form of public transport that the City of Harare should adopt, there is, however, a strong view on a mass transport system as the backbone of public transport, (Mbara, 2015)

Other measures proffered to address traffic congestion are:

2.5.2. Strict lane management

Different lanes for different types of vehicles should be marked on the roads and law and financial penalty should be imposed to make the drivers maintain the lane discipline.

2.5.3. Deterrent measures

The government can take such strict steps as imposing a financial penalty on offending drivers, pedestrian and traders. They should be made to dissuade the drivers from certain congestion causing habit such as wrong overtaking, one-way driving. Truck drivers should be fined for disobeying traffic law and driving unfit truck. This kind of implication of law can mitigate the traffic jam in short run, but in long run, all the people should be involved to create awareness and responsibility to the society.

2.5.4. Road capacity

Congestion can be reduced by either increasing road capacity (supply) or by reducing traffic (demand). Road capacity can be increased in a number of ways such as adding more capacity over the whole of a route, creating new routes, and improvements in traffic management. Reduction of demand can include, parking restriction, park, 
and ride, congestion pricing, road space rationing, incentives to use public transport and introduction of carpooling (Zhang,2011).

2.5.5. Dedicated lanes for pedestrians and cyclists

There should be dedicated lanes for pedestrians and cyclist.

2.5.6. Provision of car parks

Car parks should be created in market centres for private cars who wish to shop to use instead of parking by the roadside. There should be dedicated bus stops for public transport and taxis for picking up passengers.

\section{Study area}

Harare is the capital and most populous city of Zimbabwe, with an estimated urban population of 2.1 million as of 2012 (Census 2012). According to the Central Vehicle Registry (CVR, 2012), the number of vehicles in the country increased by approximately 6\% from 522682 in 1999 to 973188 by 2009 . Albeit the non-availability of figures by city, it is estimated that about $70 \%$ of these vehicles are in Harare. It is evident that there is a clear mismatch between increases in the number of vehicles plying the streets of Harare and provision of road space resulting in severe congestion.

The conceptual framework as shown in Fig. 1 was adopted from an ecologist Mead who used it to categorize the causes of diseases into three. His model was adapted by Jorgensen and Abane (1999) and a host of transport experts to be applied to the causes of road traffic accidents. The conceptual framework above gives the graphical model of managing traffic congestion in Harare CBD. It seeks to explain that the causes of traffic congestion in Harare $\mathrm{CBD}$, which are poor discipline, improper lane management, archaic management, poor urban planning, poor road design etc., have effects on the economy and individuals. Some of these effects on individuals are stress, road rage, etc. It affects the economy by decreasing the level of production of the economy, polluting the air, etc. However, there are measures that can be taken to reduce these effects and possibly prevent the causes of traffic congestion in Harare urban. Some of these measures are introduction of mass transit vehicles within the CBD, penalties for indiscipline to law disobeying drivers and vendors, strict lane management, dedicated lanes among others. This will decrease stress and increase productivity at both individual and national level.

Fig. 2. Triad of managing traffic congestion.

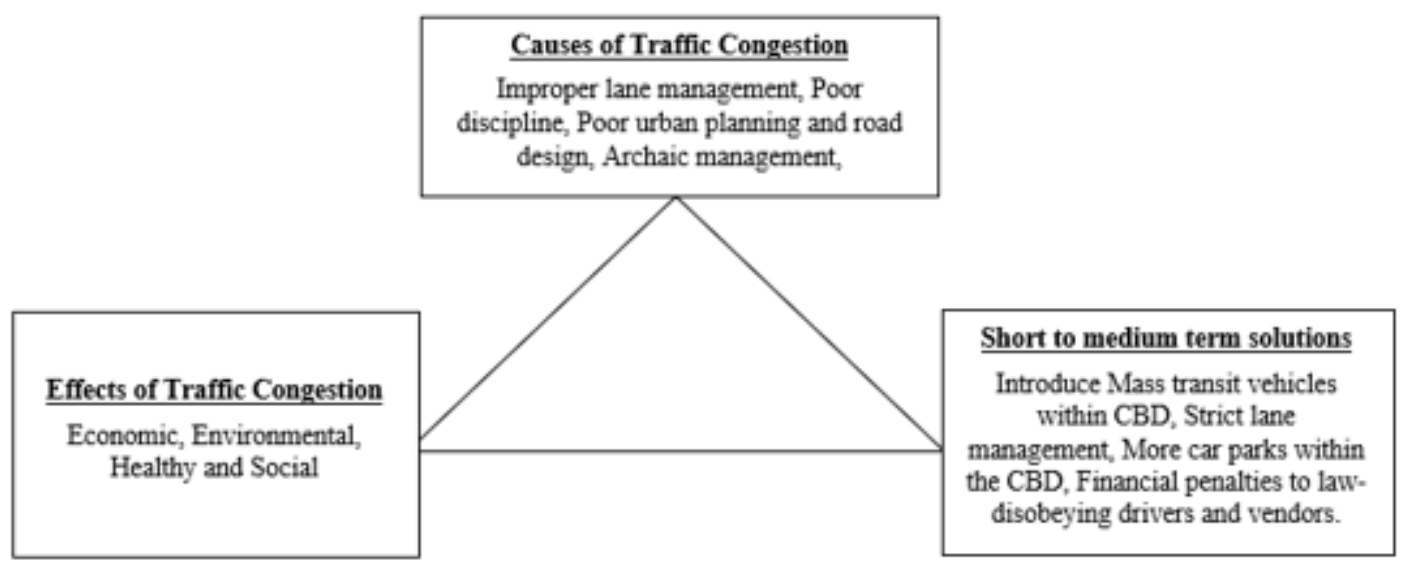

Source: Jorgensen and Abane (1999)

\section{Methodology}

\subsection{Research Design}

The exploratory research design was used for this study, which is not intended to provide conclusive evidence but to help in better understanding a phenomenon. Exploratory research tends to tackle new problems on which little or no previous research has been done (Sarantakos, 2006).

\subsection{Sample size and sampling technique}

In this study, the sample size was 385 people for a population of 2.1 million Harare City residents, assuming a 95 per cent confidence interval and a margin of error of 5 per cent. (Sample size calculator by Raosoft , 2004). In the survey part the male and female respondents had equal chances of taking part as random selection was used.An accidental sampling technique was therefore used in administering the questionnaires on 385, drivers, vendors, pedestrians, shoppers and office and industrial workers found within the Harare CBD. Seven officials from the Central Vehicle Registry (CVR) of the Zimbabwe, Harare City Council, Zimbabwe Republic Police ( ZRP), Ministry of Transport (MoT), Drivers Union, Vehicle Inspection Department(VID) and Traffic Safety of Zimbabwe also purposively interviewed. 


\subsection{Instruments}

Questionnaires, in-depth interviews (IDIs) and observational checklist were developed to collect primary data from the field. The questionnaire comprising a mix of open-ended and closed-ended was divided into five sections. Section A focused on the demographic characteristics of respondents such as gender, the level of education, occupation, etc. Section B centred on the causes of traffic congestion in Harare CBD. Section C was on the effects of traffic congestion in Harare CBD while section D focused on the measures put in place to manage traffic congestion in Harare CBD and the final section, section $\mathrm{E}$ on the possible measures needed to manage traffic congestion in Harare CBD.

The In-depth interview guide was to elicit information on causes and effects of traffic congestion and how it has been managed and how it can be managed from the officials of relevant stakeholders such as City of Harare Transport planning department, Drivers Union, Traffic Safety of Zimbabwe, Police, Ministry of Transport, Vehicle inspection Department (VID). The interview guide was in a semi-structured format in line with Sorantakos (2006) assertion that semi-structured interviews are flexible, and they allow for the exploration of emerging themes and ideas.

The study also made use of non-participant observation. With this method of data collection, observers studied the phenomenon as traffic flows within the CBD of Harare (Sarantakos, 2006). Observation checklist was prepared to guide and used to observe road traffic congestion in the study area.

\subsection{Data collection procedures}

Two research assistants were trained in a classroom environment for two days. These research assistants piloted the research instruments in order to fine-tune the research instruments at Market Square area in Harare CBD. The main fieldwork was carried out between $13^{\text {th }}$ and $20^{\text {th }}$ November 2019 . Literate respondents completed the questionnaire with little or no assistance whereas the content of the questionnaires was interpreted into Shona (the widely spoken language in Zimbabwe) for the few illiterate. Out of the 385 questionnaires administered, only 315 $(81.82 \%)$ were correctly filled and thus formed the basis for this study.

\subsection{Data analysis}

The quantitative data were analysed using the Statistical Product for Service Solutions (SPSS) v 21. Frequencies and percentages were used to present the results from the questionnaires in form of tables and charts. The IDIs were analysed manually. The data from the IDIs were transcribed, then categorized under specific themes and manually analysed.

\section{Results}

5.1. Background characteristics of respondents

As shown in Table 1 and 2, the majority of the respondents $(51.7 \%)$ were females and the mean age of respondents was 33 years old.

The majority of the respondents had attained basic education and able to read and write (89\%) and was married (49.8\%). Christianity is the dominant religion in Harare CBD. 
Table 1

Socio-demographic characteristics of respondents

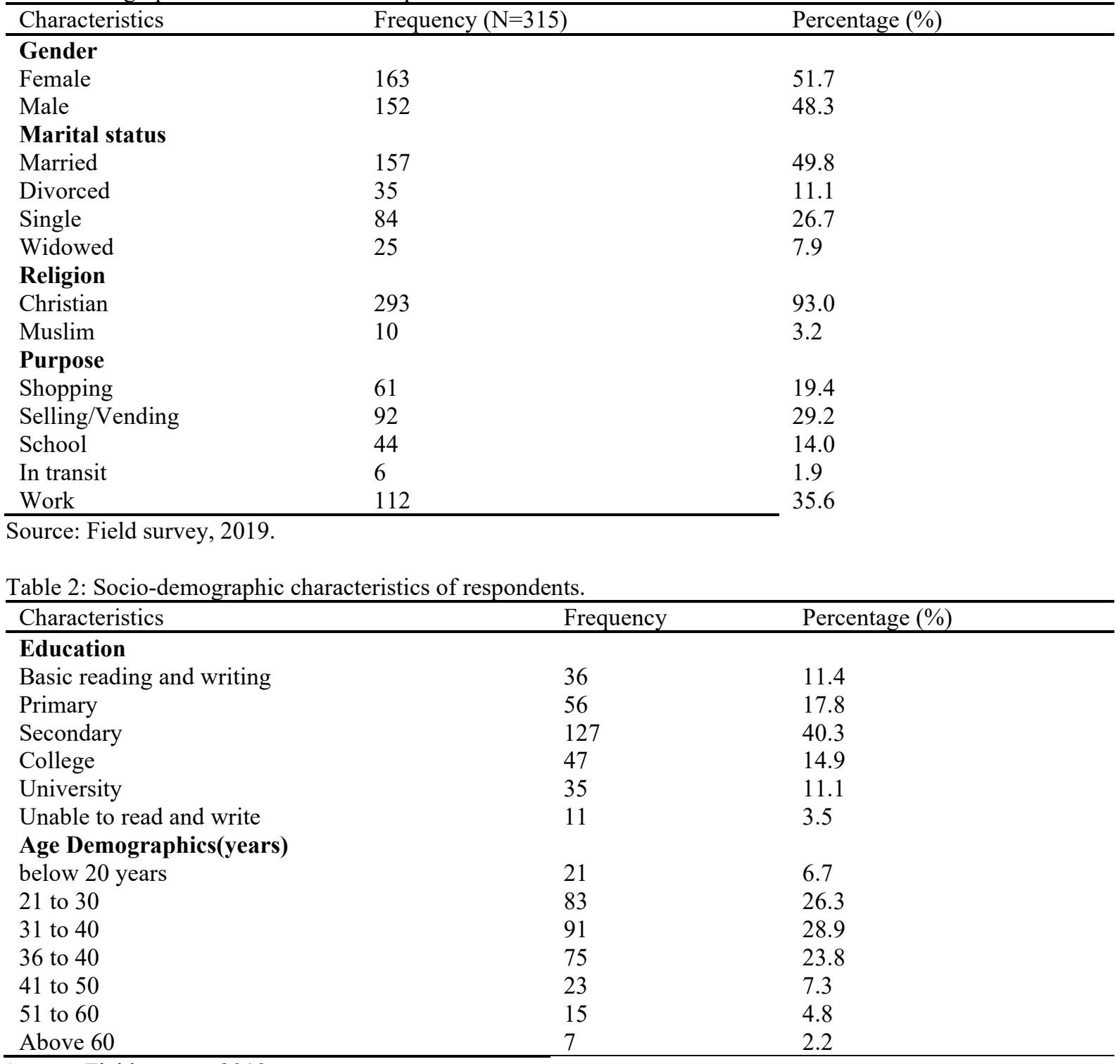

Source: Field survey, 2019.

Fig 3: Time of the day congestion is experienced

\section{Time of the day congestion is experienced}

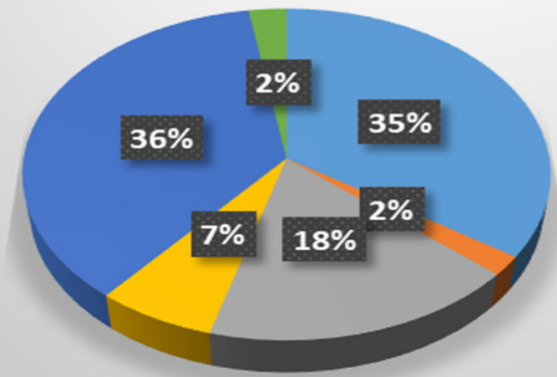

- 6am and $10 \mathrm{am}$

- $10 \mathrm{am}$ to $1 \mathrm{pm}$

$1 \mathrm{pm}$ to $2 \mathrm{pm}$

$2 \mathrm{pm}$ to $4 \mathrm{pm}$

- $4 \mathrm{pm}$ to $7 \mathrm{pm}$

$7 \mathrm{pm}$ to $10 \mathrm{pm}$

Source: Field survey, 2019. 
Table 3: Frequency and duration of traffic congestion

\begin{tabular}{lll}
\hline Variables & Frequency & Percentage \\
\hline Frequency of traffic congestion & & \\
Most frequently & 143 & 45.4 \\
Frequently & 155 & 49.2 \\
Seldom & 17 & 5.4 \\
Duration of traffic congestion & & \\
$\quad<15$ min & 14 & 4.4 \\
$16-30$ min & 69 & 21.9 \\
$31-45$ min & 108 & 34.3 \\
$46-60$ min & 71 & 22.5 \\
$>60$ & 53 & 16.8 \\
\hline
\end{tabular}

According to Fig. 3, the traffic congestion peaks are $6 \mathrm{am}$ and $10 \mathrm{am}(35 \%), 4 \mathrm{pm}$ to $7 \mathrm{pm}(36 \%)$ and goes down significantly in between the day. As shown in Table 3, more than half of the respondents experienced the traffic congestion frequently with $49.2 \%$ and $45.4 \%$ experiencing it more frequently. The Table further shows that the majority of the respondents experienced the traffic jam between 16 min and above. More than 57\% of the respondents spent 16-60 min in traffic with $16.8 \%$ spending more than 60 min.

5.2. Causes of traffic congestion

Fig 4: Causes of traffic congestion in Harare CBD

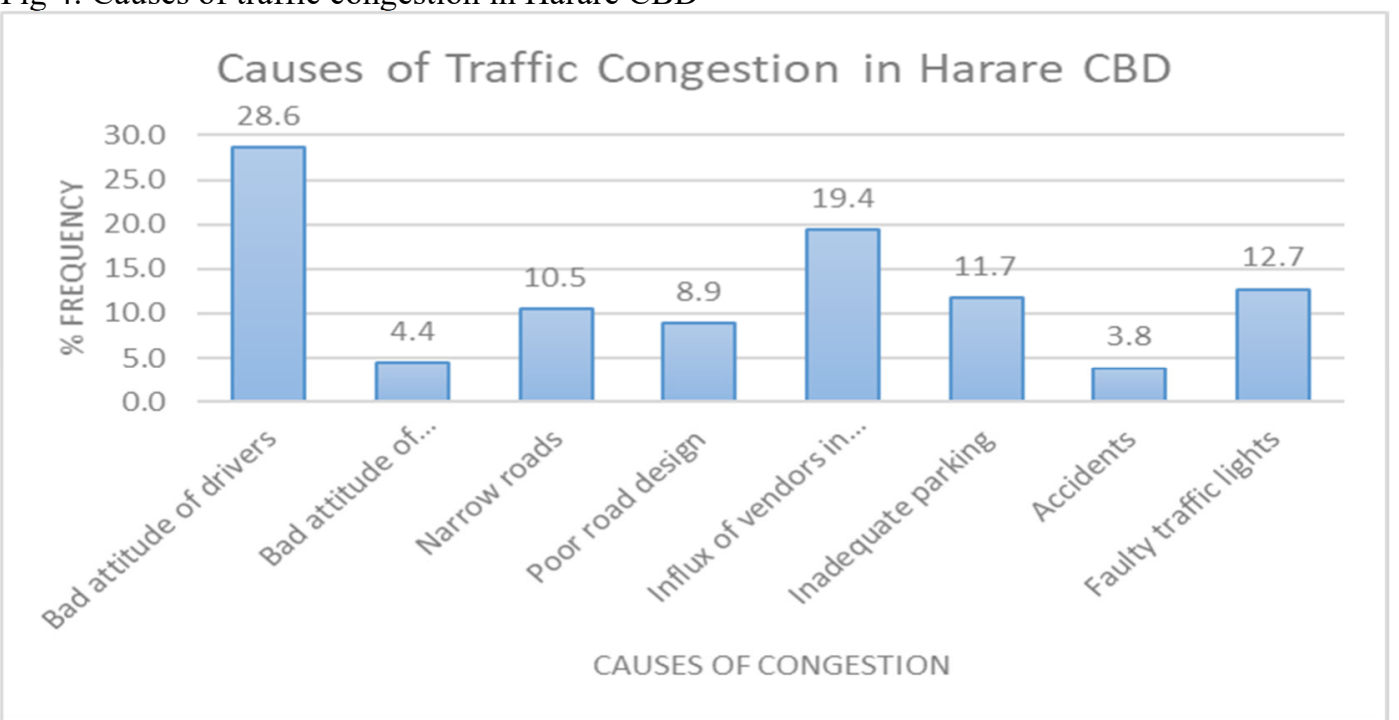

Source: Field survey, 2019.

According to Fig. 4, the bad attitudes of drivers (28.6\%), influx of vendors in streets (19.4\%), faulty traffic lights $(12.7 \%)$, inadequate parking space $(11.7 \%)$ and narrow roads $(10.5 \%)$ are the main causes of traffic congestion in Harare CBD. 
5.3. Effects of traffic congestion

Table 4: General and daily effects of traffic congestion

\begin{tabular}{lll}
\hline Characteristics & Frequency & Percentage \\
\hline General effects & & \\
Decrease in productivity & 91 & 28.9 \\
Pollution & 38 & 12.1 \\
Stress & 53 & 16.8 \\
Time consuming & 69 & 21.9 \\
Road rage & 35 & 11.1 \\
No effects & 29 & 9.2 \\
Total & 315 & 100.0 \\
Effects on daily life & & \\
Decrease in productivity & 76 & 24.1 \\
Lateness & 75 & 23.8 \\
Stress & 51 & 16.2 \\
Takes time & 68 & 21.6 \\
No effects & 45 & 14.3 \\
\hline Source: Fild & &
\end{tabular}

Source: Field survey ,2019

According to Table 4 , the majority $(28.9 \%)$ of the respondents perceived that traffic congestion decrease productivity whilst $21.9 \%$ indicated that it is time consuming. $18 \%$ opined that it causes stress. Table 4 further shows that traffic congestion affects daily life through decrease in productivity $(24.1 \%)$ and lateness $(23.8 \%)$ in their various activities.

Fig. 5. Users responsible for traffic congestion.

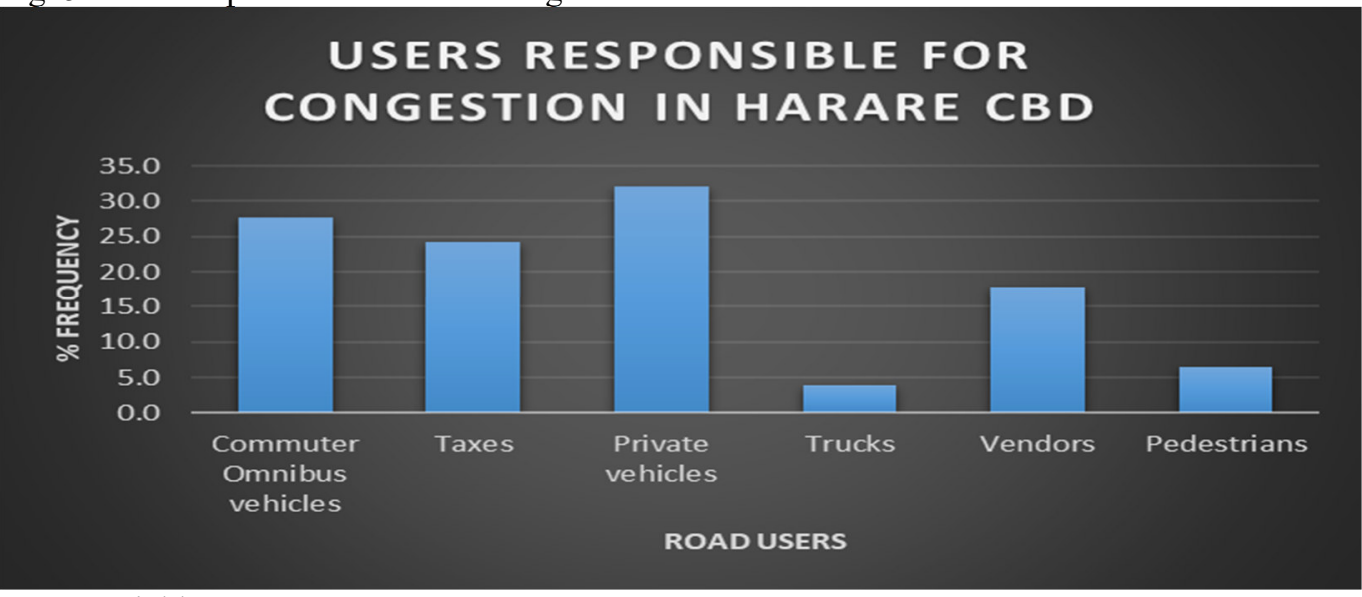

Source: Field survey, 2019

According to the survey, more than $30 \%$ of road users are private vehicles, $27.8 \%$ are commuter omnibuses, $24.2 \%$ are taxes and $17.8 \%$ are vendors. The above mentioned constitutes the majority of road users who are directly responsible for urban traffic congestion.

\subsection{Measures to manage traffic congestion}

A number of measures to tackle traffic congestion in Harare CBD were proposed by the respondents:

A vendor/street seller responded that:

"There is high level of unemployment and for the past 10 years I couldn't find any job until I decided to do vending to feed my family. City fathers must find a place to put us where there are customers like the ones in this CBD.I agree that it is not ok to be selling in streets like what we are doing now"

A taxi driver observed that:

"Most parts of the city are usually out of electricity causing congestion, police officers must always be at such traffic intersections to control vehicles, in my opinion that will reduce congestion in the CBD" A Commuter Omnibus (Combi) driver:

"I know people talk much about us Combi drivers but I think traffic lights are also constantly not working and the roads and city plan need to be redesigned. The town council must look into providing solar system on robots and turn most roads into one-way traffic lanes to reduce traffic cohesion. This will go a long way in reducing congestion in Harare".

A pedestrian stated:

"Evacuating vendors from the streets, providing traffic lights and controlling of commuter omnibuses 
within the CBD will help manage traffic congestion in the city of Harare".

A Transport planner at the Ministry of Transport:

"The road infrastructure has limited capacity so when there is frequent congestion the lifespan of the road and pavements will reduce, and more money will be spent for maintenance and reconstruction. Our institution is a policy-making institution. We make policies, which are turned into strategies, which are also turned into activities. There are agencies put in place to implement these policies. Example when it comes to road safety, the Traffic Safety Council of Zimbabwe is there to ensure safety on the roads by educating the public. In the same regard mass transit vehicle system is currently on the table to reduce urban congestion".

\section{Discussion}

Traffic congestion is a global nagging phenomenon confronting cities (Mbara,2015). This could be current and non-current traffic congestion (Andoh, 2014). However, current traffic congestion is found in CBDs as it occurs at a particular place, time and daily. This is generally the consequence of factors that act regularly on the transportation system such as daily commuting to work, shop, school or sell. These are users that experience the traffic congestion on daily commuting.

Rapid increases in car ownership in addition to poor land use planning, inadequate road space, lack of regulated parking systems, bad attitude of pedestrians, and motorists cause traffic congestions globally ( Kiunsi, 2013). In Harare CBD, the causes of traffic congestion are poor road networks, pedestrian obstruction, trading obstruction, narrow traffic lanes, reserved parking lots and load and picking of passengers along the road (bad attitude of drivers)

Bad attitude of drivers such a wrong overtaking, one-way driving, disobeying traffic signals and dropping and picking of passengers have been identified as causes of traffic congestion.

Illegal parking reduces the size of the existing narrow road and encroaches on the pedestrian walkway if any. The pedestrians struggle with other users such as traders and motorists to use the small portion of the road left after the incursion by illegal on-street parking.

In the study, traders and commuter omnibuses are responsible for almost half of the traffic congestion occurring in Harare CBD Traders/hawkers/vendors have taken over pedestrian walkways and even portions of the road to showcase their wares to shoppers. This inadvertently causes pedestrian and motorists to share the already narrow roads in market centres (Abane, 1993).

The external effects of traffic congestion are broadly categorized as environmental, health, economic and social ( Mahmud et al., 2012). Most studies have always laid emphasized on the economic burden of traffic congestion to the individual and the economy in both the developed and developing countries (Levy et al., 2010). This is substantiated in the study where the majority of the respondents noted the experiencing traffic congestion is time-consuming as a major externality. For instance, in the US, time wasted in traffic leads to an economic burden ranging from 83 -124 billion dollars (Victoria Transport Policy Institute, 2009). To the driver timeconsuming externality of traffic congestion means an increase in fuel consumption, which leads to higher transportation costs and to the worker it is wastage of working time and delay in service delivery which results in financial losses (Kiunsi, 2013).

Traffic congestion in Harare CBD cannot be prevented but rather managing it to an acceptable level (Mbara 2015). Managing traffic congestion in the Harare CBD calls for a multi-faceted approach (Mbara 2015). Recommendations applicable to the Harare CBD are:

- Improvement/provision of pedestrian walkway

- Introducing urban transit vehicles within the CBD and design outskirt parking or drop and pick of commuter omnibuses

- Retraining/enforcement of personnel to handle the traffic problems

- Provision of parking lots

- Continuous education on the effects of bad driving (that can be handled by Traffic safety of Zimbabwe)

- Lane management or/and vehicular flow through traffic management

- Banning of traders/hawkers on the streets

\section{Conclusions and policy implications}

From the study, it can be concluded that the ranked causes of traffic congestion in Harare CBD are the bad attitude of traders, narrow roads, bad attitude of drivers, poor road design, bad attitude of pedestrians and accidents. The effects of traffic congestion are time-consuming, pollution and stress, decreased productivity. Measures to be put in place to manage traffic congestion in Harare CBD are multifaceted.

There is no holistic measure to tackle traffic congestion in Harare CBD. The municipal police must wield its power to evacuate street sellers/vendors/hawkers on the street with the provision of personnel of the ZRP to arrest offenders and a special court to prosecute to serve as a deterrent to others. 
Display of wares by traders/vendors on pedestrian walkway should be discouraged and offenders are to be fined or their wares seized by the ZRP personnel. All these measures should be effected in the city by-laws so that the police may have powers of rest in case of breach.

\section{References}

Abane, A. M. (1993). Tackling traffic congestion in Accra, Ghana: A road user's perspective. Journal of Advanced Transportation, 27(2), 193-206.

Abane, A. M. (2011). Travel behavior in Ghana: Empirical observations from four metropolitan areas. Journal of Transport Geography, 19(1), 313-322.

Andoh, A. K. (2014). Managing road traffic congestion in the Cape coast metropolis, Ghana (Masters dissertation). university of cape coast.

Currie, J., \& Walker, R. (2011). Traffic congestion and infant health: Evidence from E-Z Pass. American Economic Journal: Applied Economics, 3(1), 65-90.

Downie (2008). The world worst traffic jams time. (Retrieved on 02 ${ }^{\text {nd }}$ November 2019) Available at. 〈http://www.time/world/article/0,8599,1733872.html〉.

Essandoh, P. K., \& Armah, F. A. (2011). Determination of ambient noise levels in the main commercial area of Cape Coast, Ghana. Research Journal of Environmental and Earth Sciences, 3(6), 637-644.

Government of Zimbabwe. (1993). Economic Structural Adjustment Programme.Harare: Government Printers.

Kiunsi, R. B. (2013). A review of traffic congestion in Dar es Salaam city from the physical planning perspective. Journal of Sustainable Development, 6(2), 94.

Levy, J. I., Buonocore, J. J., \& Von Stackelberg, K. (2010). Evaluation of the public health impacts of traffic congestion: A health risk assessment. Environmental Health, 9(1), 65.

Mahendra, A. (2009). Vehicle restrictions in four Latin American cities: Is congestion pricing possible? Transport Review, 28, 105-133.

Mahmud, K., Gope, K., \& Chowdhury, S. M. R. (2012). Possible causes \& solutions of traffic jam and their impact on the economy of Dhaka City. Journal of Management and Sustainability, 2(2), 112-135.

Mensah, J., Annan, J., \& Baidoo, F. (2014). Assessing the impact of vehicular traffic on energy demand in the Accra Metropolis. Journal of Management Policy and Practice, 15(4), 127.

Mbara T,C (2015) Achieving Sustainable Urban Transport in Harare, Zimbabwe: What are the Requirements to Reach the Milestone? University of Johannesburg,, Journal of Transport and Supply Chain Management.

Rahane, S. K., \& Saharkar, U. R. (2014). Traffic congestion-causes and solutions: A study of Talegaon Dabhade city. Journal of Information, Knowledge and Research in Civil Engineering, 3(1), 160-163.

Rodrigue, J. P., Comtois, C., \& Slack, B. (2009). The geography of transportation system. New York: Routledge. Sarantakos, S. (2006). Social research (4th Ed). London: Macmillan Press Ltd.

Schrank, D., \& Lomax, T. (2005). The 2005 Annual Urban Mobility Report. Texas: Texas Transportation Institute.

Shamsher, R., \& Abdullah, M. N. (2015). Traffic congestion in Bangladesh-causes and solutions: A study of Chittagong metropolitan city. Asian Business Review, 2(1), 13-18.

Texas Transportation Institute (TTI) (2011). The keys to estimating mobility in urban areas: Applying definitions and measures that everybody understands. Texas: Texas Transportation Institute.

The Herald ,25 February 2018 (Zimbabwean Newspaper).

Victoria Transport Policy Institute (2009). Transportation cost and benefit analysis: Techniques. Victoria, BC, Canada: Estimates and Implications.

Yildirim, M. B. (2001). Congestion toll pricing models and methods for variable demand networks (Doctoral dissertation). University of Florida.

ZHANG, W., 2011. Managing Traffic Congestion Case Study of Hangzhou. European Spatial

Planning and Regional Development, Blekinge Institute of Technology. 